Article

\title{
In Vitro Evaluation of the Antiviral Activity of the Synthetic Epigallocatechin Gallate Analog-Epigallocatechin Gallate (EGCG) Palmitate against Porcine Reproductive and Respiratory Syndrome Virus
}

\author{
Chunjian Zhao ${ }^{1,2,3, \dagger}$, Shuaihua Liu ${ }^{1,2,3, \dagger}$, Chunying $\mathrm{Li}^{1,2,3, *}$, Lei Yang ${ }^{1,2,3}$ and \\ Yuangang $\mathrm{Zu}{ }^{1,2,3, *}$
}

1 State Engineering Laboratory for Bio-Resource Eco-Utilization, Northeast Forestry University, Harbin 150040, China; E-Mails: zcjsj@163.com (C.Z.); woshiliushuaihua@163.com (S.L.); ylnefu@163.com (L.Y.)

2 Key Laboratory of Forest Plant Ecology, Ministry of Education, Northeast Forestry University, Harbin 150040, China

3 Engineering Research Center of Forest Bio-Preparation, Ministry of Education, Northeast Forestry University, Harbin 150040, China

$\dagger$ These authors contributed equally to this work.

* Authors to whom correspondence should be addressed; E-Mails: nefujane@aliyun.com (C.L.); zuyuangang@yahoo.com.cn (Y.Z.); Tel./Fax: +86-451-8219-0848 (C.L);

Tel.: +86-451-8219-1387 (Y.Z.); Fax: +86-451-8210-2082 (Y.Z.).

Received: 27 November 2013; in revised form: 13 January 2014 / Accepted: 12 February 2014 / Published: 21 February 2014

\begin{abstract}
In this study, epigallocatechin gallate (EGCG) palmitate was synthesized and its anti-porcine reproductive and respiratory syndrome virus (PRRSV) activity was studied. Specifically, EGCG palmitate was evaluated for its ability to inhibit PRRSV infection in MARC-145 cells when administered as pre-, post-, or co-treatment. EGCG and ribavirin were used as controls. The results showed that a $50 \%$ cytotoxic concentration (CC50) of EGCG, EGCG palmitate, and ribavirin was achieved at 2,359.71, 431.42, and $94.06 \mu \mathrm{M}$, respectively. All three drugs inhibited PRRSV in a dose-dependent manner regardless of the treatment protocol. EGCG palmitate exhibited higher cytotoxicity than EGCG, but lower cytotoxicity than ribavirin. EGCG palmitate anti-PRRSV activity was significantly higher than that of EGCG and ribavirin, both as pre-treatment and post-treatment. Under the former conditions and a tissue culture infectious dose of 10 and 100, the selectivity
\end{abstract}


index (SI) of EGCG palmitate in the inhibition of PRRSV was 3.8 and 2.9 times higher than that of ribavirin when administered as a pre-treatment, while the SI of EGCG palmitate in the inhibition of PRRSV was 3.0 and 1.9 times higher than ribavirin when administered as a post-treatment. Therefore, EGCG palmitate is potentially effective as an anti-PRRSV agent and thus of interest to the pharmaceutical industry.

Keywords: EGCG palmitate; synthesized; anti-PRRSV; MARC-145 cells

\section{Introduction}

Porcine reproductive and respiratory syndrome (PRRS), commonly known as blue-eared pig disease, is an infectious disease characterized by severe reproductive deficiency in pregnant sows and by respiratory symptoms in piglets [1]. It is caused by porcine reproductive and respiratory syndrome virus (PRRSV), an important swine pathogen which, since its discovery in the early 1990s, has quickly spread throughout pig-breeding countries, causing large economic losses [2,3]. PRRSV is an enveloped, single-stranded, positive-sense RNA virus and a member of the order Nidovirales, family Arteriviridae [4]. As a macrophage-tropic virus, it establishes a chronic infection in these cells in vivo and replicates in primary pig macrophages in vitro [5]. Pigs persistently infected with PRRSV develop viremia, with reduced cellular immunity [6]. The main routes of PRRS infection are respiratory transmission, airborne transmission, airborne spread, contact transmission, and semen transmission. Current antiviral strategies fail to prevent and control PRRSV, such that infected pigs typically become long-term carriers of the virus [7]. Thus, there is a clear need to develop effective anti-PRRSV drugs.

(-)-Epigallocatechin-3-gallate (EGCG), the major catechin extracted from tea, exhibits potent inhibitory effects on many viruses, such as influenza virus, hepatitis B virus, hepatitis $\mathrm{C}$ virus (HCV), and human immunodeficiency virus (HIV) [8-14]. In preliminary experiments, EGCG demonstrated anti-PRRSV activity in vitro, although significant effects were achieved only at relatively high concentrations, probably because of the drug's poor chemical stability and rapid decomposition [15]. Esterification of EGCG is an effective means to improve its stability [16]. Ribavirin is a well-known and broad-spectrum antiviral drug that was previously shown to dose-dependently inhibit PRRSV replication [17-19]. Thus, in the present study, the anti-PRRSV activity of EGCG palmitate was evaluated. EGCG and ribavirin served as the positive controls.

\section{Results}

\subsection{Chemical Structure of EGCG Palmitate}

An EGCG derivative was synthesized and identified as EGCG palmitate by MS, IR, UV, and ${ }^{1}$ H-NMR. EGCG palmitate is composed of a mixture of four regioisomers (a:b:c:d = 20:20:18:44); its chemical structure is shown in Figure 1 and is consistent with that previously reported [20]. 
Figure 1. The chemical structure of epigallocatechin gallate (EGCG) and EGCG palmitate.

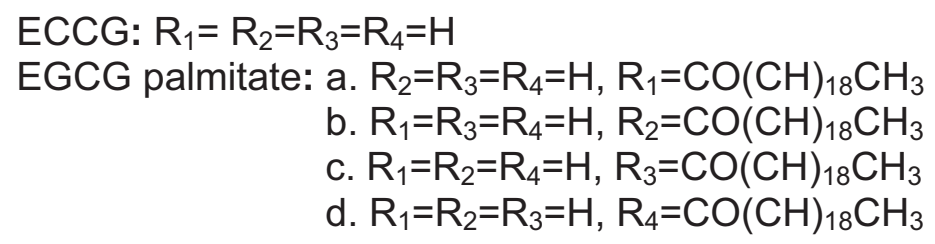<smiles>[R20]Oc1cc(C(=O)O[C@H]2Cc3c(O)cc(O)cc3O[C@H]2c2cc([R20])c(O[R2])c(O)c2)cc(O)c1O[R20]</smiles>

\subsection{Cytotoxicity of EGCG, EGCG Palmitate, and Ribavirin}

The cytotoxicity of different concentrations of EGCG $(0-5452.75 \mu \mathrm{M})$, EGCG palmitate $(0-1148.80 \mu \mathrm{M})$, and ribavirin $(0-409.84 \mu \mathrm{M})$ in MARC-145 cells was tested in an MTT assay. The cells were treated with each of the three drugs for $72 \mathrm{~h}$, after which the cell inhibition ratio was evaluated. As shown in Figure 2, the inhibitory effect of EGCG, EGCG palmitate, and ribavirin on cell growth was dose-dependent, with a 50\% cytotoxic concentration (CC50) of 2359.71, 431.42, and $94.06 \mu \mathrm{M}$, respectively.

Figure 2. Cytotoxicity of EGCG, EGCG palmitate, and ribavirin in MARC-145 cells.

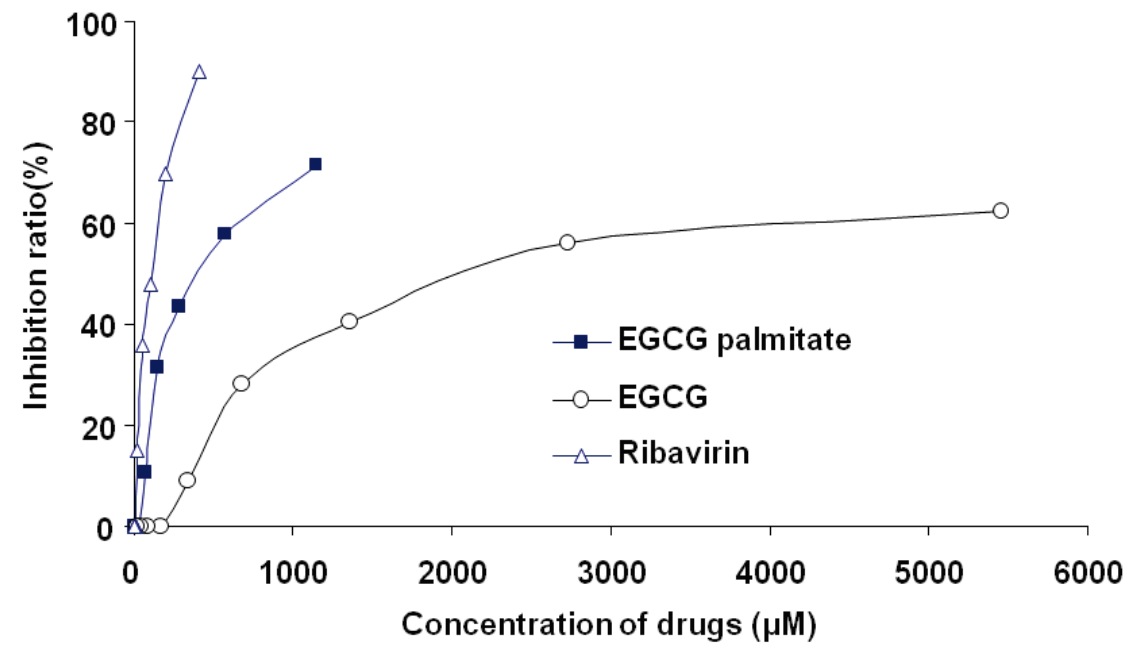

Figure 3 shows the morphology of the treated MARC-145 cells. Compared with the controls (Figure 3a), EGCG palmitate, at a concentration of $17.95 \mu \mathrm{M}$ (Figure 3b), did not show any proliferation-inhibiting activity. As the concentration of EGCG palmitate increased, the gaps between 
the plated cells increased as well (Figure 3c,d). Since $17.95 \mu \mathrm{M}$ EGCG palmitate did not induce obvious cell toxicity; it was used as the maximum initial concentration in further experiments. For EGCG and ribavirin, the corresponding concentrations were $170.40 \mu \mathrm{M}$ and $12.81 \mu \mathrm{M}$, respectively.

Figure 3. Optical microscopy photographs of cultured MARC-145 cells $(\times 100)$. The cells were incubated with (a) cell culture medium (control group), and either $17.95 \mu \mathrm{M}$ (b), $287.20 \mu \mathrm{M}$ (c), or $1148.80 \mu \mathrm{M}$ (d) EGCG palmitate.
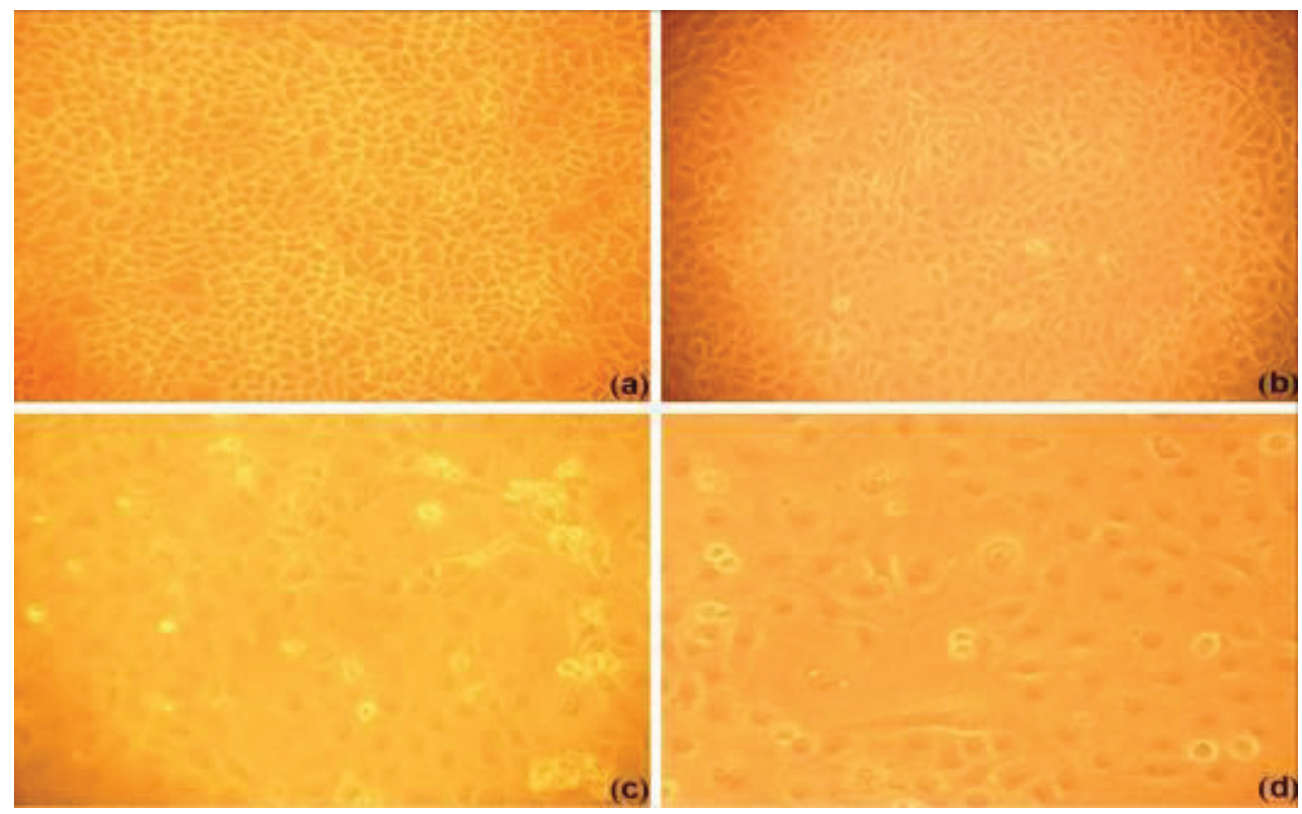

\subsection{The TCID50 of PRRSV}

The final cytopathic effects (CPE) resulting from the different concentrations of PRRSV were recorded until the infected cells no longer developed lesions and the control cells were still intact and clearly distinguishable. As shown in Table 1, the 50\% tissue culture infective dose (TCID50) according to the Reed-Muench method was 10-3.85 [21].

Table 1. Cytopathic effect of porcine reproductive and respiratory syndrome virus (PRRSV) on MARC-145 cells.

\begin{tabular}{cccccc}
\hline Dilution & $\begin{array}{c}\text { Infected } \\
\text { well }\end{array}$ & $\begin{array}{c}\text { Uninfected } \\
\text { well }\end{array}$ & $\begin{array}{c}\text { Cumulative } \\
\text { infected well }\end{array}$ & $\begin{array}{c}\text { Cumulative } \\
\text { uninfected well }\end{array}$ & Infected (\%) \\
\hline $10^{-1}$ & 6 & 0 & 20 & 0 & $100(20 / 20)$ \\
$10^{-2}$ & 6 & 0 & 14 & 0 & $100(14 / 14)$ \\
$10^{-3}$ & 5 & 1 & 9 & 1 & $90(9 / 10)$ \\
$10^{-4}$ & 3 & 3 & 3 & 4 & $42.8(3 / 7)$ \\
$10^{-5}$ & 0 & 6 & 0 & 10 & $0(0 / 10)$ \\
$10^{-6}$ & 0 & 6 & 0 & 16 & $0(0 / 16)$ \\
$10^{-7}$ & 0 & 6 & 0 & 22 & $0(0 / 22)$ \\
$10^{-8}$ & 0 & 6 & 0 & 28 & $0(0 / 28)$ \\
$10^{-9}$ & 0 & 6 & 0 & 28 & $0(0 / 28)$ \\
\hline
\end{tabular}




\subsection{Cytopathic Effect of PRRSV on MARC-145 Cells Pre-Treated with the Test and Control Compounds}

To investigate whether PRRSV infection is reduced in MARC-145 cells pretreated with either EGCG, EGCG palmitate, or ribavirin, a CPE method was used. As shown in Figure 4, the three compounds reduced PRRSV infection in a dose-dependent manner. Their EC50 and selectivity index (SI) values in reducing PRRSV infection are provided in Table 2, which shows that EGCG palmitate more strongly reduced PRRSV infection than either EGCG or ribavirin, in accordance with their SIs.

Figure 4. Cytopathic effect of PRRSV on MARC-145 cells pre-treated with EGCG (a), EGCG palmitate (b), and ribavirin (c).
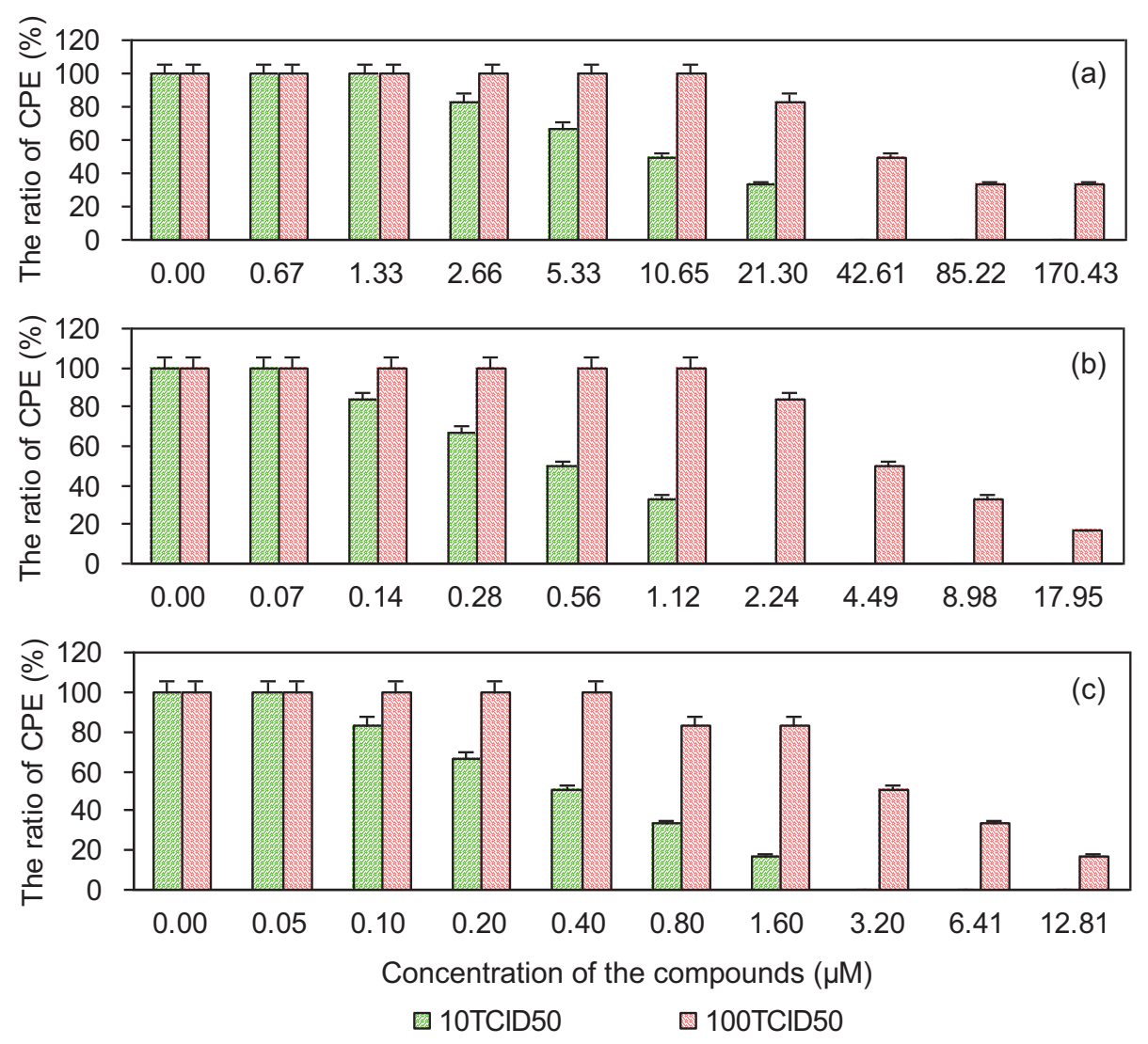

Table 2. Cytopathic effect of PRRSV on MARC-145 cells pre-treated with the test and control compounds.

\begin{tabular}{|c|c|c|c|c|}
\hline \multirow{2}{*}{ Compounds } & \multicolumn{2}{|c|}{10 TCID $_{50}$} & \multicolumn{2}{|c|}{100 TCID $_{50}$} \\
\hline & $\mathrm{EC}_{50}(\mu \mathrm{M})^{\mathrm{a}}$ & SI $^{\mathbf{b}}$ & $\mathrm{EC}_{50}(\mu \mathrm{M})$ & SI \\
\hline EGCG & 8.53 & 276.62 & 60.25 & 39.16 \\
\hline EGCG palmitate & 0.48 & 892.29 & 5.53 & 77.96 \\
\hline Ribavirin & 0.40 & 234.98 & 3.48 & 27.02 \\
\hline
\end{tabular}

${ }^{\mathrm{a}} \mathrm{EC}_{50}$ is the concentration that reduced the virus-induced CPE by $50 \% ;{ }^{\mathrm{b}} \mathrm{SI}$ (selectivity index) is the ratio of $\mathrm{CC}_{50}$ to $\mathrm{EC}_{50}$. 


\subsection{Cytopathic Effect of PRRSV in MARC-145 Cells Post-Treated with the Test and Control Compounds}

As shown in Figure 5, the cytopathic effect of PRRSV was reduced in MARC-145 cells post-treated with EGCG palmitate. The EC50 and SI values of EGCG, EGCG palmitate, and ribavirin are shown in Table 3. Greater inhibition of PRRSV was achieved with EGCG palmitate than with either EGCG or ribavirin, in accordance with their SIs.

Figure 5. Cytopathic effect of PRRSV in MARC-145 cells post-treated with EGCG (a), EGCG palmitate (b), and ribavirin (c).
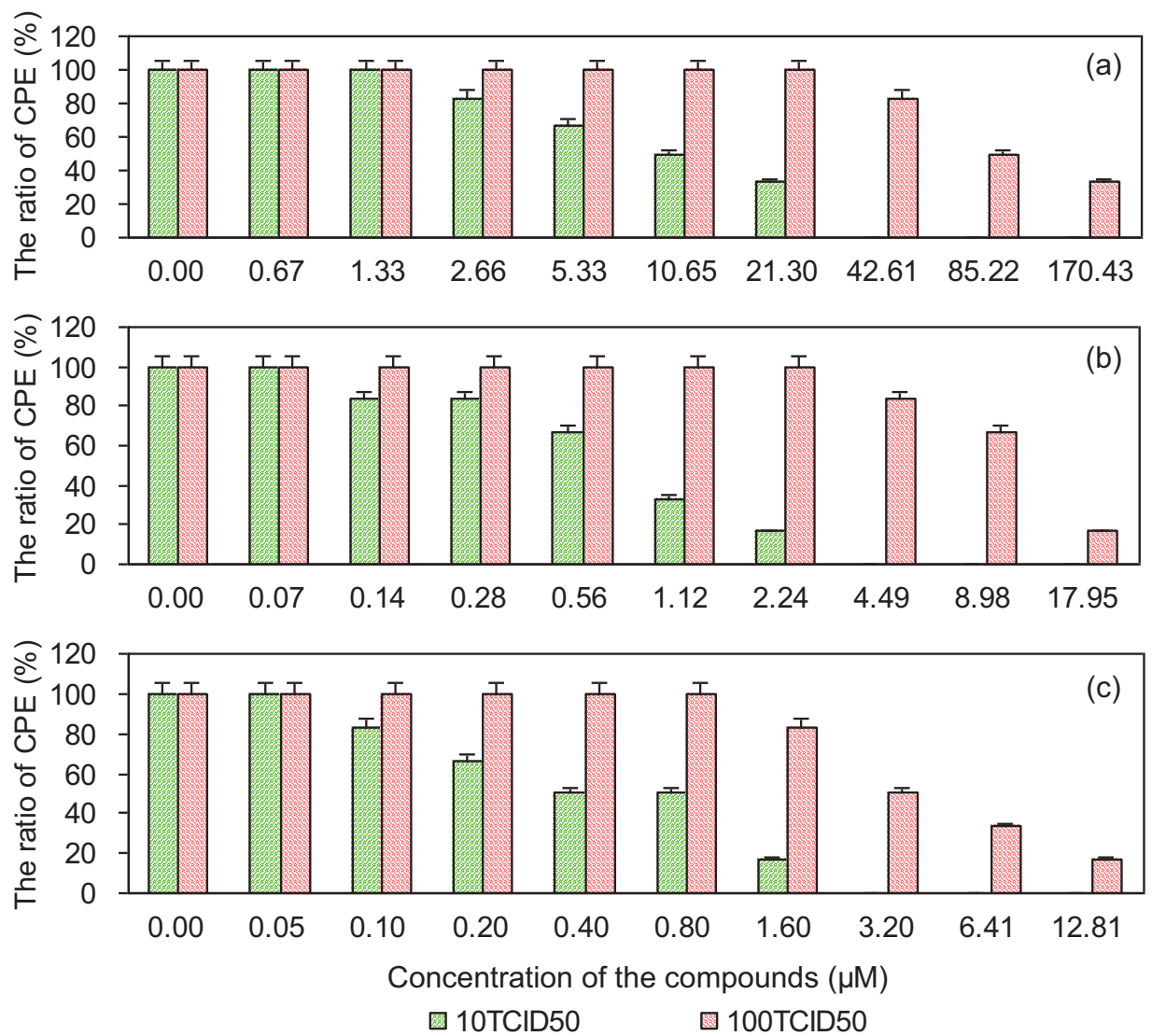

Table 3. Cytopathic effect of PRRSV in MARC-145 cells post-treated with the test and control compounds.

\begin{tabular}{ccccc}
\hline \multirow{2}{*}{ Compounds } & \multicolumn{2}{c}{$\mathbf{1 0 ~ T C I D}_{\mathbf{5 0}}$} & \multicolumn{2}{c}{$\mathbf{1 0 0}_{\mathbf{~ T C I D}} \mathbf{5 0}$} \\
\cline { 2 - 5 } & $\mathbf{E C}_{\mathbf{5 0}}(\boldsymbol{\mu} \mathbf{M})^{\mathbf{a}}$ & $\mathbf{S I}^{\mathbf{b}}$ & $\mathbf{E C}_{\mathbf{5 0}}(\boldsymbol{\mu} \mathbf{M})$ & $\mathbf{S I}$ \\
\hline EGCG & 9.18 & 257.01 & 97.88 & 24.11 \\
EGCG palmitate & 0.68 & 635.93 & 9.43 & 45.75 \\
Ribavirin & 0.44 & 212.71 & 3.95 & 23.82 \\
\hline
\end{tabular}

\subsection{Cytopathic Effect of PRRSV on MARC-145 Cells Co-Treated with the Test and Control Compounds}

As shown in Figure 6, in co-treated cells, EGCG palmitate inhibited PRRSV in a dose-dependent manner. The $\mathrm{EC}_{50}$ and SI values of EGCG, EGCG palmitate, and ribavirin in their inhibition of 
PRRSV are shown in Table 4. Ribavirin more strongly inhibited PRRSV activity than either EGCG or EGCG palmitate, in accordance with the SIs of the three drugs.

Figure 6. The cytopathic effect of PRRSV in MARC145 cells co-treated with EGCG (a), EGCG palmitate (b), and ribavirin (c).
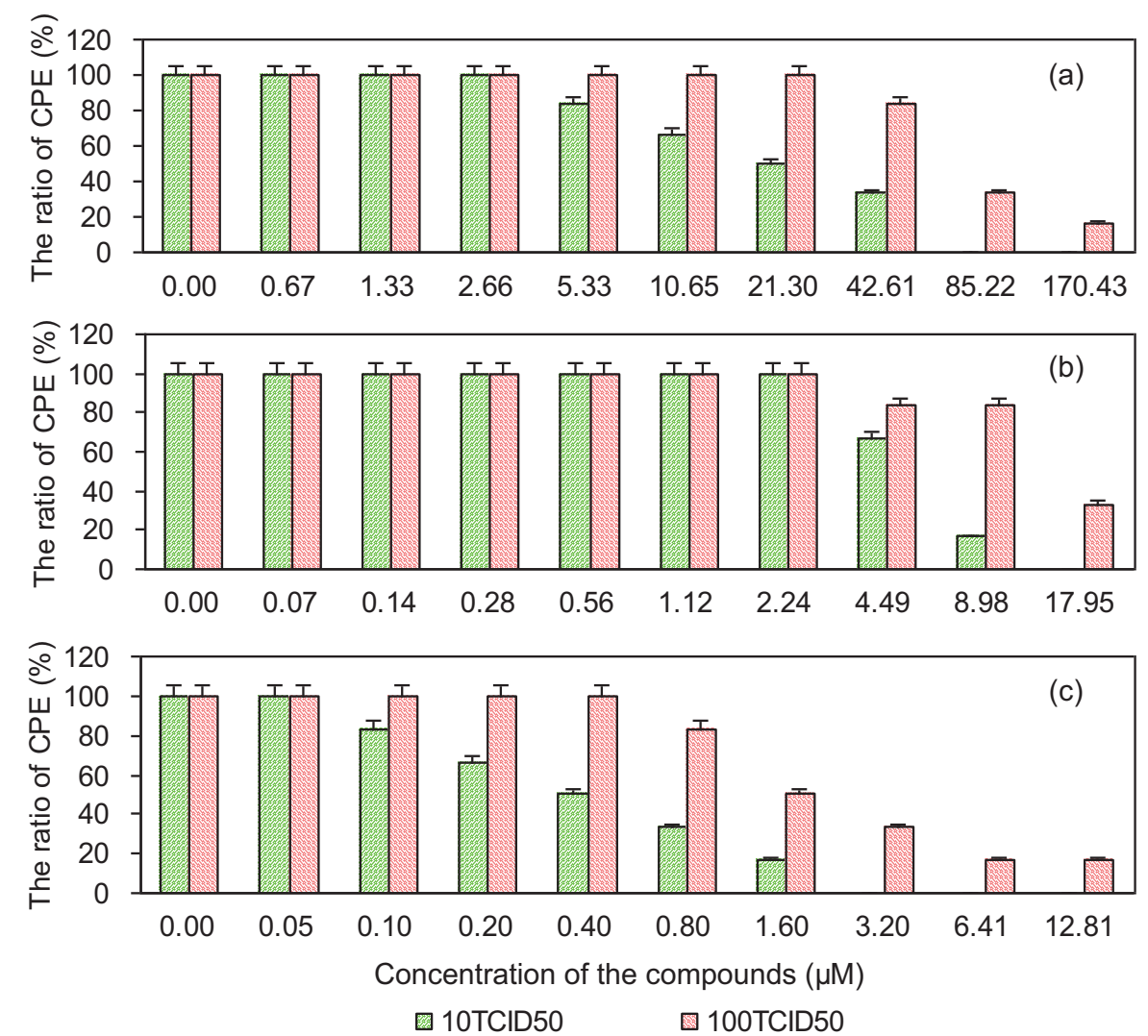

Table 4. Cytopathic effect of PRRSV in MARC-145 cells co-treated with the test and control compounds.

\begin{tabular}{ccccc}
\hline \multirow{2}{*}{ Compounds } & \multicolumn{2}{c}{ 10TCID $_{\mathbf{5 0}}$} & \multicolumn{2}{c}{ 100TCID $_{\mathbf{5 0}}$} \\
\cline { 2 - 5 } & $\mathbf{E C}_{\mathbf{5 0}}(\boldsymbol{\mu} \mathbf{M})^{\mathbf{a}}$ & $\mathbf{S I}^{\mathbf{b}}$ & $\mathbf{E C}_{\mathbf{5 0}}(\boldsymbol{\mu} \mathbf{M})$ & SI \\
\hline EGCG & 18.36 & 128.50 & 66.23 & 35.63 \\
EGCG palmitate & 5.86 & 73.64 & 12.69 & 33.99 \\
Ribavirin & 0.40 & 234.98 & 2.21 & 42.58 \\
\hline
\end{tabular}

\section{Discussion}

EGCG exerts inhibitory effects on many viruses. At concentrations between 1 and $10 \mathrm{mM}$, EGCG inhibited the in vitro infectivity of both influenza A and influenza B virus in Madin-Darby canine kidney cells. An electron microscopy study showed that EGCG prevented viral adsorption to these cells [22]. Two recent studies found that EGCG inhibited the cellular attachment of HCV, thus disrupting the initial step of viral entry and suggesting both an antiviral strategy in the treatment of $\mathrm{HCV}$ infection and the prevention of $\mathrm{HCV}$ reinfection after liver transplantation [11,12]. EGCG also 
inhibited HIV-1 infectivity in human CD4(+) $\mathrm{T}$ cells by preventing the attachment of HIV -1 glycoprotein 120 to CD4 molecules on T cells [23]. However, EGCG is unstable in culture media, with a half-life of less than $30 \mathrm{~min}$ [15].

To increase the stability of EGCG, Mori et al. prepared a series of EGCG fatty acid monoesters and then demonstrated that, of these, the anti-influenza virus activity EGCG palmitate was dramatically enhanced. Specifically, the antiviral activity of EGCG palmitate against influenza A/PR8/34 (H1N1) virus was 24-fold higher than that of native EGCG [24]. Kaihatsu found that EGCG palmitate inhibited human and avian influenza A and B viruses, including those that were drug-resistant. EGCG palmitate was found to be more effective than neuraminidase inhibitors and was much better than zanamivir and osertamivir phosphate in inhibiting the infection of chicken eggs by avian influenza (H5N2) virus [25].

Based on previous in vivo and in vitro findings in the MARC-145 cell culture system, the CPE of aqueous extracts from teas on PRRS was assessed [26]. In that study, PRRSV was killed and the development of PRRS thus inhibited. In preliminary experiments, EGCG showed anti-PRRSV activity in vitro. Given the chemical instability of EGCG, in this study the more stable EGCG palmitate was synthesized and its anti-PRRSV activity was evaluated. In accordance with the SI values, our results showed that the anti-PRRSV activity of EGCG palmitate was the significantly greater than that of either EGCG or ribavirin. The anti-viral activity of EGCG palmitate was much stronger as a pre-treatment than as a co-treatment or post-treatment compound. Thus, EGCG palmitate may inhibit viral adsorption and cell intrusion.

\section{Experimental}

\subsection{Materials and Chemicals}

MARC-145 cells were obtained from BioHermes Bio-Pharmaceutical Technology Co., Ltd. (Wuxi, China). PRRSV was obtained from Dr. Yonggang Liu at the Harbin Veterinary Research Institute, Chinese Academy of Agricultural Sciences (Harbin, China).

EGCG (98\%), ribavirin, dimethyl sulfoxide (DMSO), and 3-(4,5-dimethylthiazol-2-yl)-2,5diphenyltetrazolium bromide (MTT), palm chloride, and pyridine were obtained from Sigma-Aldrich Shanghai Trading Co., Ltd. (Shanghai, China). Minimal essential medium (MEM) was purchased from Shanghai DoBio Biotech Co., Ltd. (Shanghai, China). Other chemicals were purchased from Beijing Chemical Reagents Company (Beijing, China).

\subsection{The Synthesis, Preparation, and Identification of EGCG Palmitate}

EGCG palmitate was prepared as described elsewhere [27]. Briefly, 0.92 g EGCG was added to $100 \mathrm{~mL}$ ethyl acetate, followed by $20 \mathrm{~mL}$ of palm chloride and $2.0 \mathrm{~mL}$ pyridine at room temperature. The ingredients were mixed in a magnetic blender for $5 \mathrm{~h}$ at $300 \mathrm{rpm}$.

After termination of the reaction, the sample was filtered through a $0.45-\mu \mathrm{m}$ membrane and purified by silica gel column chromatography (silica gel and ethyl acetate/hexane as stationary and mobile phase, respectively). The absorbance of the eluent was measured at $280 \mathrm{~nm}$ in a UV spectrophotometer; according to the elution curve. The eluent corresponding to the main peak was combined, concentrated, and dried for identification. The predominant fraction was identified by MS (Esi, 
Absciex, Api-3000), IR (KBr, Nicolet, Magna-560), UV (Shimadzu, UV-2550), and ${ }^{1} \mathrm{H}-\mathrm{NMR}\left(\mathrm{CDCl}_{3}\right.$, Bruker, Avance-300 MHz). The isolated pure compound was used in the anti-PRRSV analysis.

\subsection{Cell Culture}

MARC-145 cells were cultured in a $25-\mathrm{cm}^{2}$ cell culture flask in MEM containing $10 \%$ fetal bovine serum and $1 \%$ penicillin-streptomycin in a humidified incubator containing $5 \% \mathrm{CO}_{2}$ at $37{ }^{\circ} \mathrm{C}$. The cells were subcultured until they reached the exponential growth phase and then plated in 96-well culture plates for cytotoxicity and anti-PRRSV assays. The cells were propagated at $37{ }^{\circ} \mathrm{C}$ in an atmosphere of $5 \% \mathrm{CO}_{2}[28]$.

\subsection{Cytotoxicity Testing of EGCG, EGCG Palmitate, and Ribavirin}

The cytotoxicity of EGCG, EGCG palmitate, and ribavirin was investigated using a 3-(4,5-dimethylthiazol-2-yl)-2,5-diphenyltetrazolium bromide (MTT) assay [29,30]. The cells were suspended in $200 \mu \mathrm{L}$ of $2 \%$ MEM in 96-well plates. After $24 \mathrm{~h}$ of incubation, $200 \mu \mathrm{L}$ of medium containing different concentrations of EGCG, EGCG palmitate, or ribavirin was added to the wells, followed by incubation for $72 \mathrm{~h}$. The EGCG concentrations were 21.30, 42.60, 85.20, 170.40, 340.80, $681.59,1,363.19,2,726.38$, and 5,452.75 $\mu \mathrm{M}$. The EGCG palmitate concentrations were 4.49, 8.98, $17.95,35.90,71.80,143.60,287.20,574.40$, and $1,148.80 \mu \mathrm{M}$. The ribavirin concentrations were 1.60, $3.20,6.40,12.81,25.62,51.23,102.46,204.92$, and $409.84 \mu \mathrm{M}$. Medium without any compound was used as a control. To evaluate cell viability, $20 \mu \mathrm{L}$ of MTT solution $(5 \mathrm{mg} / \mathrm{mL}$ in $\mathrm{NaCl})$ was added to the wells, which were further incubated for $4 \mathrm{~h}$ at $37{ }^{\circ} \mathrm{C}$ in a humidified atmosphere containing $5 \%$ $\mathrm{CO}_{2}$. After the remaining medium was removed, $150 \mu \mathrm{L}$ of DMSO was added to each well to solubilize the precipitate. The resulting absorbance, which is proportional to the number of viable cells, was measured at $490 \mathrm{~nm}$ using a microplate reader (Awareness, STAT FAX 2100).

\subsection{PRRSV Titration}

MARC-145 cells were seeded onto 96-well plates for $24 \mathrm{~h}$ before infection. The PRRSV supernatants were 10 -fold serially diluted, from $10^{-1}$ to $10^{-9}$, and $200 \mu \mathrm{L}$ of each dilution was added to each of six wells. Cell maintenance medium without PRRSV was used as a control. The cells were incubated at $37{ }^{\circ} \mathrm{C}$ for $72 \mathrm{~h}$ in an incubator containing $5 \% \mathrm{CO}_{2}$. The cell cytopathic effect (CPE) was observed daily under an inverted microscope [31]. The 50\% tissue culture infective dose $\left(\mathrm{TCID}_{50}\right)$ was calculated by the Reed-Muench method [21].

\subsection{The Effect of EGCG Palmitate on PRRSV in Vitro}

The effect of EGCG palmitate on PRRSV was investigated in three different experiments.

Pre-treatment with EGCG palmitate: On the basis of the maximal non-cytotoxic concentration, EGCG palmitate was prepared and $200 \mu \mathrm{L}$ was added to a monolayer of MARC-145 cells plated in 96-well plates. The plates were then incubated at $37{ }^{\circ} \mathrm{C}$ for $4 \mathrm{~h}$ in an atmosphere containing $5 \% \mathrm{CO}_{2}$. The EGCG palmitate solution was removed and replaced with the virus solution, which was allowed to 
adsorb for $1.5 \mathrm{~h}$. The virus solution was then removed and the cells were washed once with $\mathrm{NaCl}$; subsequently, $200 \mu \mathrm{L}$ of cell maintenance medium was added to each well and the plates were incubated for $72 \mathrm{~h}$ as described above. The CPE was then determined.

Post-treatment with EGCG palmitate: A monolayer of MARC-145 cells plated in 96-well plates was treated with $200 \mu \mathrm{L}$ of EGCG palmitate and the plates were incubated at $37{ }^{\circ} \mathrm{C}$ for $1.5 \mathrm{~h}$ in an incubator containing 5\% $\mathrm{CO}_{2}$. The virus solution was removed and the cells were washed once with $\mathrm{NaCl}$. Subsequently, $200 \mu \mathrm{L}$ of the different concentrations of EGCG palmitate were added to each well and the plates were then incubated at $37^{\circ} \mathrm{C}$ for $72 \mathrm{~h}$ in an incubator containing $5 \% \mathrm{CO}_{2}$. The $\mathrm{CPE}$ was then determined [31].

Co-treatment with EGCG palmitate: EGCG palmitate was mixed with isometric virus solution and the mixture was incubated at $37^{\circ} \mathrm{C}$ for $2 \mathrm{~h}$. A monolayer of MARC-145 cells plated in 96-well plates was then treated with $200 \mu \mathrm{L}$ of the mixture and the plates were incubated as described above for $1.5 \mathrm{~h}$. The supernatant was removed and the cells were washed once with $\mathrm{NaCl}$. Subsequently, $200 \mu \mathrm{L}$ of cell maintenance medium was added to each well and the plates were incubated for $72 \mathrm{~h}$ in $5 \% \mathrm{CO}_{2}$ at $37^{\circ} \mathrm{C}$. The $\mathrm{CPE}$ was then determined.

Each process in the three above-described experiments was repeated six times. The controls consisted of cells treated in the same way but with EGCG or ribavirin. The antiviral effect is expressed as the concentration that decreased the virus-induced $\mathrm{CPE}$ by $50 \%\left(50 \%\right.$ effective concentration, $\left.\mathrm{EC}_{50}\right)$.

\section{Conclusions}

In this work, EGCG palmitate was shown to possess dose-dependent anti-PRRSV activity in vitro. The cytotoxicity of EGCG palmitate was higher than that of EGCG but its anti-PRRSV activity was significantly higher than that of either EGCG or ribavirin when added as a pre- or post-treatment. The results were in agreement with the determined SI values. In particular, the anti-PRRSV activity of EGCG palmitate was much stronger when the drug was added as a pre-treatment than as either a post- or co-treatment. Thus, EGCG palmitate is of interest to the pharmaceutical industry since administration of this inhibitor may prevent PRRSV infection in pigs.

\section{Acknowledgments}

This work was financially supported by the Fundamental Research Funds for the Central Universities (No. DL12EA01-04, DL12CA05), the Natural Science Foundation of Heilongjiang Province (No. C201024) and the postdoctoral science-research development foundation of Heilongjiang province (No. LBH-Q11177), China.

\section{Author Contributions}

Chunjian Zhao contributed to the study design, data acquisition and analysis. Shuaihua Liu contributed to data acquisition and drafted the manuscript. Chunying Li contributed to the study design and revised the manuscript. Lei Yang was involved in data acquisition and revision of the manuscript. Yuangang $\mathrm{Zu}$ reviewed and edited the manuscript. All authors have read and approved the final manuscript. 


\section{Conflicts of Interest}

The authors declare no conflict of interest.

\section{References and Notes}

1. Prieto, C.; Castro, J.M. Porcine reproductive and respiratory syndrome virus infection in the boar: A review. Theriogenology 2005, 63, 1-16.

2. Bao, Y.H.; Guo, Y.C.; Zhang, L.Y.; Zhao, Z.H.; Li, N. Inhibition of porcine reproductive and respiratory syndrome virus replication by RNA interference in MARC-145 cells. Mol. Biol. Rep. 2012, 39, 2515-2522.

3. Snijder, E.J.; Meulenberg, J.J. The molecular biology of arteriviruses. J. Gen. Virol. 1998, 79, 961-979.

4. Xiao, S.A.; Wang, Q.W.; Gao, J.T.; Wang, L.L.; He, Z.Y.; Mo, D.L.; Liu, X.H.; Chen, Y.H. Inhibition of highly pathogenic PRRSV replication in MARC-145 cells by artificial microRNAs. Virol. J. 2011, 8, e491.

5. William, A.C.; Richard, G.D.; Grace, H.W.; Suleman, S.; Pam, W.D.; Raymond, R.R.; Eric, A.N. Porcine reproductive and respiratory syndrome virus (PRRSV) infection spreads by cell-to-cell transfer in cultured MARC-145 cells, is dependent on an intact cytoskeleton, and is suppressed by drug-targeting of cell permissiveness to virus infection. Virol. J. 2006, 3, e90.

6. Hu, J.; Ni, Y.; Dryman, B.A.; Meng, X.J.; Zhang, C. Immunogenicity study of plant-made oral subunit vaccine against porcine reproductive and respiratory syndrome virus (PRRSV). Vaccine 2012, 30, 2068-2074.

7. Neumann, E.J.; Kliebenstein, J.B.; Johnson, C.D.; Mabry, J.W.; Bush, E.J.; Seitzinger, A.H.; Green, A.L.; Zimmerman, J.J. Assessment of the economic impact of porcine reproductive and respiratory syndrome on swine production in the United States. J. Am. Vet. Med. Assoc. 2005, 227, 385-392.

8. Song, J.M.; Lee, K.H.; Seong, B.L. Antiviral effect of catechins in green tea on influenza virus. Antivir. Res. 2005, 68, 66-74.

9. Xu, J.; Wang, J.; Deng, F.; Hu, Z.; Wang, H. Green tea extract and its major component epigallocatechin gallate inhibits hepatitis B virus in vitro. Antivir. Res. 2008, 78, 242-249.

10. Kawai, K.; Tsuno, N.H.; Kitayama, J.; Okaji, Y.; Yazawa, K.; Asakage, M.; Hori, N.; Watanabe, T.; Takahashi, K.; Nagawa, H. Epigallocatechin gallate, the main component of tea polyphenol, binds to CD4 and interferes with gp120 binding. J. Allergy Clin. Immunol. 2003, 112, 951-957.

11. Ciesek, S.; von Hahn, T.; Colpitts, C.C.; Schang, L.M.; Friesland, M.; Steinmann, J.; Manns, M.P.; Ott, M.; Wedemeyer, H.; Meuleman, P.; et al. The green tea polyphenol, epigallocatechin-3-gallate, inhibits hepatitis C virus entry. Hepatology 2011, 54, 1947-1955.

12. Calland, N.; Albecka, A.; Belouzard, S.; Wychowski, C.; Duverlie, G.; Descamps, V.; Hober, D.; Dubuisson, J.; Rouillé, Y.; Séron, K. (-)-Epigallocatechin-3-gallate is a new inhibitor of hepatitis $\mathrm{C}$ virus entry. Hepatology 2012, 55, 720-729. 
13. Chen, C.; Qiu, H.; Gong, J.; Liu, Q.; Xiao, H.; Chen, X.W.; Su, B.L. Yang, R.G. (-)-Epigallocatechin-3-gallate inhibits the replication cycle of hepatitis C virus. Arch. Virol. 2012, 157, 1301-1312.

14. Steinmann, J.; Buer, J.; Pietschmann, T.; Steinmann, E. Anti-infective properties of epigallocatechin-3-gallate (EGCG), a component of green tea. Br. J. Pharmacol. 2013, 168, 1059-1073.

15. Hong, J.; Lu, H.; Meng, X.; Ryu, J.H.; Hara, Y.; Yang, C.S. Stability, cellular uptake, biotransformation, and efflux of tea polyphenol (-)-epigallocatechin-3-gallate in HT-29 human colon adenocarcinoma cells. Cancer Res. 2002, 62, 7241-7246.

16. Ying, Z.; Fereidoon, S. Lipophilised epigallocatechin gallate (EGCG) derivatives and their antioxidant potential in food and biological systems. Food Chem. 2012, 131, 22-30.

17. Ogbomo, H.; Michaelis, M.; Altenbrandt, B.; Doerr, H.W.; Cinatl, J. A novel immunomodulatory mechanismof ribavirin in suppressing natural killer cell function. Biochem. Pharmacol. 2010, 79, $188-197$.

18. Hu, H.; Zhang, X.; Zhang, H.; Wen, G.; Tong, C.; Li, X.; Fang, W. Molecular characterization of three porcine reproductive and respiratory syndrome virus isolates and their susceptibility to antiviral drugs. Pak. Vet. J. 2013, in press.

19. Kim, Y.; Lee, C. Ribavirin efficiently suppresses porcine nidovirus replication. Virus Res. 2013, 171, 44-53.

20. Matsumura, K.; Kaihatsu, K.; Mori, S.; Cho, H.H.; Kato, N.; Hyon, S.H. Enhanced antitumor activities of (-)-epigallocatechin-3-O-gallate fatty acid monoester derivatives in vitro and in vivo. Biochem. Biophys. Res. Commun. 2008, 3, 1118-1122.

21. Reed, L.J.; Muench, H. A simple method of estimating fifty percent endpoints. Am. J. Epidemiol. 1938, 27, 493-497.

22. Nakayama, M.; Suzuki, K.; Toda, M.; Okubo, S.; Hara, Y.; Shimamura, T. Inhibition of the infectivity of influenza virus by tea polyphenols. Antivir. Res. 1993, 21, 289-299.

23. Nance, C.L.; Siwak, E.B.; Shearer, W.T. Preclinical development of the green tea catechin, epigallocatechin gallate, as an HIV-1 therapy. J. Allergy. Clin. Immunol. 2009, 123, 459-465.

24. Mori, S.; Miyake, S.; Kobe, T.; Nakaya, T.; Fuller, S.D.; Kato, N.; Kaihatsu, K. Enhanced anti-influenza A virus activity of (-)-epigallocatechin-3-O-gallate fatty acid monoester derivatives: Effect of alkyl chain length. Bioorg. Med. Chem. Lett. 2008, 18, 4249-4252.

25. Kaihatsu, K.; Mori, S.; Matsumura, H.; Daidoji, T.; Kawakami, C.; Kurata, H.; Nakaya, T.; Kato, N. Broad and potent anti-influenza virus spectrum of epigallocatechin-3-O-gallate-monopalmitate. J. Mol. Genet. Med. 2009, 3, 195-197.

26. Zhou, H.R.; Tang, Q.W.; Yu, X.L.; Li, R.C.; Luo, W.; Jiang, D.L.; Ge, M. Antiviral effect of aqueous extracts of four kinds of tea on porcine reproductive and respiratory syndrome virus. J. Hunan Agric. Univ. 2012, 38, 305-309.

27. Chen, P.; Sun, D.; Zheng, X.M. Preparation, structure and antioxidant activity of EGCG palmitate. J. Zhejiang Univ. (Sci. Edition) 2003, 30, 422-425.

28. Ran, Z.G.; Chen, X.Y.; Guo, X.; Ge, X.N.; Yoon, K.J.; Yang, H.C. Recovery of viable porcine reproductive and respiratory syndrome virus from an infectious clone containing a partial deletion within the Nsp2-encoding region. Arch. Virol. 2008, 153, 899-907. 
29. Zhang, X.; Wang, X.; Mu, L.; Ding, Z. Immune responses in pigs induced by recombinant DNA vaccine co-expressing swine IL-18 and membrane protein of porcine reproductive and respiratory syndrome virus. Int. J. Mol. Sci. 2012, 13, 5715-5728.

30. Xu, J.M.; Song, S.T.; Tang, Z.M.; Jiang, Z.F.; Liu, X.Q.; Zhou, L.; Zhang, J.; Liu, X.W. Predictive chemotherapy of advanced breast cancer directed by MTT assay in vitro. Breast Canc. Res. Treat. 1999. 53, 77-85.

31. Erica, S.; Carol, B. Cytopathic effects of viruses protocols. Available online: http://www. microbelibrary.org/component/resource/laboratory-test/2875-cytopathic-effects-of-viruses-protocols/ (accessed on 22 July 2012).

(C) 2014 by the authors; licensee MDPI, Basel, Switzerland. This article is an open access article distributed under the terms and conditions of the Creative Commons Attribution license (http://creativecommons.org/licenses/by/3.0/). 